\title{
Are frequent dental x-ray examinations associated with increased risk of vestibular schwannoma?
}

\author{
Clinical article
}

\author{
Yueh-Ying Han, Ph.D., ${ }^{1}$ Oren Berkowitz, PH.D., M.S.P.H., P.A.-C., ${ }^{1,2}$ \\ Evelyn Talbott, Dr.P.H., ${ }^{1}$ Douglas Kondziolka, M.D., ${ }^{2}$ \\ Maryann Donovan, Ph.D., M.P.H., ${ }^{3}$ ANd L. Dade Lunsford, M.D. ${ }^{2}$
}

${ }^{1}$ Department of Epidemiology, Graduate School of Public Health, University of Pittsburgh; ${ }^{2}$ Department of Neurological Surgery, Center for Image Guided Neurological Surgery, School of Medicine, University of Pittsburgh and University of Pittsburgh Medical Center; and ${ }^{3}$ Department of Pathology, School of Medicine, University of Pittsburgh and University of Pittsburgh Cancer Institute, Pittsburgh, Pennsylvania

\begin{abstract}
Object. The authors evaluated the potential role of environmental risk factors, including exposure to diagnostic or therapeutic radiation and to wireless phones that emit nonionizing radiation, in the etiology of vestibular schwannoma (VS).

Methods. A total of 343 patients with VSs who underwent Gamma Knife surgery performed between 1997 and 2007 were age and sex matched to 343 control patients from the outpatient degenerative spinal disorders service at the University of Pittsburgh Medical Center. The authors obtained information on previous exposure to medical radiation, use of wireless phone technologies, and other environmental factors thought to be associated with the development of a VS. Conditional multivariate logistic regression was used to estimate adjusted odds ratios (aORs) and 95\% confidence intervals (CIs).

Results. After adjusting for race, education, cigarette smoking, alcohol consumption, occupational exposure to noise, use of cell phones, and family history of cancer, the authors identified only a single factor that was associated with a higher risk of VS: individuals exposed to dental $\mathrm{x}$-rays once a year $(\mathrm{aOR}=2.27,95 \% \mathrm{CI}=1.01-5.09)$ or once every $2-5$ years $(\mathrm{aOR}=2.65,95 \% \mathrm{CI}=1.20-5.85)$, compared with those exposed less than once every 5 years. Of interest, a history of exposure to radiation related to head or head-and-neck computed tomography was associated with a reduced risk of VS $(\mathrm{aOR}=0.52,95 \% \mathrm{CI}=0.30-0.90)$. No relationship was found between the use of cell phones or cordless phones and VS.

Conclusions. Patients with acoustic neuromas reported significantly more exposure to dental x-rays than a matched cohort control group. Reducing the frequency of dental x-ray examinations may decrease the potential risk of VS.
\end{abstract}

(http://thejns.org/doi/abs/10.3171/2012.5.GKS12615)

\begin{tabular}{|c|c|c|}
\hline $\begin{array}{l}\text { KEY WORDS } \\
\text { dental x-ray }\end{array}$ & $\begin{array}{ll}\text { - } & \text { vestibular schwannoma } \\
\text { - } & \text { matched case-control study }\end{array}$ & $\begin{array}{ll}- & \text { diagnostic radiation } \\
\text { y } & \bullet \quad \text { stereotactic radiosurgery }\end{array}$ \\
\hline
\end{tabular}

$\mathrm{W}$

ITH the exception of the genetic suppressor gene deletion found in patients with neurofibromatosis Type $2,{ }^{18}$ risk factors associated with the development of VS are largely unknown. Frequent exposure to loud noise was associated with the development of this lesion in the Swedish and French populations in the INTERPHONE Study. ${ }^{69}$ Although epidemiological evidence linking the risk of VS and wireless phone use is inconclusive, the World Heath Organization/International Agency for Research on Cancer classified radiofre-

\footnotetext{
Abbreviations used in this paper: $\mathrm{aOR}=$ adjusted odds ratio; $\mathrm{VS}$ $=$ vestibular schwannoma.
}

quency electromagnetic fields as "possibly carcinogenic" to humans (Group 2B) based on an increased risk for glioma associated with wireless phone use. ${ }^{10}$ Cigarette smoking, ${ }^{2}$ family history of cancer ${ }^{8}$ history of allergies and autoimmune diseases, ${ }^{4}$ previous head injuries,${ }^{19}$ and electrical appliance use ${ }^{11}$ have all been evaluated as possibly associated with the development of VSs.

Diagnostic radiation, including dental x-ray imaging, full-mouth or panorex radiological examinations, CT imaging, and fractionated radiation therapy, have been increasingly identified as sources of radiation exposure in the general population. ${ }^{1}$ These diagnostic techniques contribute to earlier detection of diseases; however, the 
effect of these medical uses of ionizing radiation and the etiology of brain tumors is unclear. The aim of the present study, as part of a larger epidemiological study of the risk factors associated with VS, was to investigate whether reported exposure to various diagnostic and therapeutic forms of radiation or nonionizing radiation from wireless phones was increased in patients with known VSs.

\section{Methods}

\section{Study Design}

A hospital-based 1:1 matched case-control study was conducted between 2009 and 2010. This study received approval from the University of Pittsburgh Institutional Review Board, and informed consent was obtained from all study participants. Sample size was calculated based on $80 \%$ power and an $\alpha$ statistic of 0.05 in a 1:1 matched case-control study.

Cases of VS were recruited from the database of patients who had undergone outpatient stereotactic radiosurgery using a Leksell Gamma Knife (Elekta AB) at the University of Pittsburgh Medical Center. A total of 822 patients with VSs underwent Gamma Knife surgery between 1997 and 2007. Patients with neurofibromastosis Type 2 and patients living outside the North American continent were excluded from the study. Study participation consent forms and a health-and-exposure questionnaire were mailed to 712 patients. Four hundred twenty patients $(59 \%)$ completed the questionnaire or were interviewed over the phone by a trained recruiter.

Controls were selected from patients examined at the outpatient degenerative spinal disorders service at the same institution and were matched by sex and age $( \pm 5$ years) to the cohort of patients with VSs. All control patients had been scheduled for outpatient evaluation of cervical or lumbar spine disorders. Controls were excluded if they had a prior diagnosis of a brain tumor or any current symptoms suggestive of a VS (such as unilateral hearing loss, tinnitus, balance disorders, or episodic vertigo). A trained recruiter distributed the questionnaire to participants who met the inclusion criteria. Participants completed the questionnaire while awaiting their outpatient appointment with a member of the neurosurgery spinal disorders team. Upon final 1:1 matching, 343 cases of VS and 343 control cases were included in the final data analysis.

\section{Exposure Assessment}

Both the patients with VS and the control patients completed the structured questionnaire. The questionnaire was designed to collect participants' demographic characteristics, a history of ionizing and nonionizing radiation exposure, and other factors reported to be associated with the development of a VS. The demographic characteristics that were collected included age, sex, race, education, marital and employment status, and the state where the patient resided at the time of completion of the questionnaire (residency). Detailed information was solicited regarding exposure to medical ionizing radiation, including frequency of dental x-ray examinations, full-mouth or panorex x-ray examinations, CT studies of the head and neck, and any other x-ray examinations or previous therapeutic radiation treatment directed to the head or neck region. The use of wireless phone technologies, including a history of cell phone and cordless phone use, was also evaluated. Participants who reported using a cell phone for at least 1 call per week for 6 months or more were defined as regular users. Exposure status was assessed before the date of diagnosis of VS and was based on self-reporting. Patients who had undergone at least 1 dental x-ray or full-mouth or panorex x-ray examination were defined as having been "ever" exposed to any dental or full-mouth or panorex x-ray. Patients who had undergone at least $1 \mathrm{CT}$ study of the head and neck, any prior $\mathrm{x}$ ray examination, or therapeutic irradiation of the head or neck region were defined as having been "ever" exposed to ionizing radiation. The questionnaire also collected information on occupational exposure to loud noise, lifestyle factors such as cigarette smoking and alcohol consumption, medical history of an earlier head injury and chronic and immunological disorders, and family history of cancer.

\section{Data Analysis}

A bivariate analysis for VS and potential confounders was estimated by performing the McNemar test for a matched case-control study. To evaluate the association between environmental or radiation exposure and VS, we applied a conditional multivariate logistic regression to estimate the aORs and 95\% CIs that would account for potential confounders. Based on the results of the bivariate analyses, the model included race, education, residency, cigarette smoking, alcohol consumption, regular use of a cell phone, occupational exposure to noise, history of hay fever and diabetes, and family history of cancer. Age of exposure to full-mouth or panorex x-ray examinations, CT scanning, and any other x-ray examination or therapeutic radiation of the head or neck region were not included in the multivariate analyses due to the high percentage of unknown responses. A separate multivariate analysis was conducted to identify any relationship between the use of cell phones or cordless phones and VS. All tests were performed at the 0.05 significance level. We used the software program IBM SPSS Statistics (version 19.0, IBM Inc.) for statistical analyses.

\section{Results}

The demographic characteristics of the study participants are shown in Table 1. The average age of patients at the time of interview was 52.9 years in cases of VS and 52.3 years in control cases. Sex was equally distributed between the 2 patient groups. More than $90 \%$ of all participants were white. We found no differences in either marital or employment status between patients with VSs and control patients. The bivariate analyses shown in Table 2 demonstrate differences between the VS population and the spinal disorder control population. The highest level of education was reported to be $\geq 13$ years by $64.1 \%$ of patients with VSs and by $35.3 \%$ of the controls. More than $50 \%$ of the patients with VSs were not residents of Penn- 
Y. Y. Han et al.

TABLE 1: Demographic characteristics of patients with vestibular schwannoma and control patients

\begin{tabular}{|c|c|c|c|c|}
\hline \multirow[b]{2}{*}{ Variable } & \multicolumn{2}{|c|}{ VS Group (343 patients) } & \multicolumn{2}{|c|}{ Control Group (343 patients) } \\
\hline & No. of Patients & $\%$ & No. of Patients & $\%$ \\
\hline \multicolumn{5}{|l|}{ age at diagnosis (yrs) } \\
\hline$<50$ & 126 & 36.7 & 131 & 38.2 \\
\hline $50-64$ & 164 & 47.8 & 157 & 45.8 \\
\hline$\geq 65$ & 53 & 15.5 & 55 & 16.0 \\
\hline mean $\pm S D$ & $52.9 \pm 12.4$ & & $52.3 \pm 12.6$ & \\
\hline \multicolumn{5}{|l|}{ sex } \\
\hline male & 169 & 49.3 & 169 & 49.3 \\
\hline female & 174 & 50.7 & 174 & 50.7 \\
\hline \multicolumn{5}{|l|}{ race } \\
\hline white & 333 & 97.1 & 315 & 91.8 \\
\hline black/African American & 2 & 0.6 & 15 & 4.4 \\
\hline other & 8 & 2.3 & 13 & 3.8 \\
\hline \multicolumn{5}{|l|}{ education (yrs) } \\
\hline$\leq 9$ & 93 & 27.1 & 170 & 49.6 \\
\hline $10-12$ & 30 & 8.7 & 52 & 15.2 \\
\hline$\geq 13$ & 220 & 64.1 & 121 & 35.3 \\
\hline \multicolumn{5}{|l|}{ marital status } \\
\hline never married & 28 & 8.2 & 27 & 7.9 \\
\hline married/partner & 270 & 78.7 & 251 & 73.2 \\
\hline separated/divorced/widowed & 45 & 13.1 & 65 & 19.0 \\
\hline \multicolumn{5}{|l|}{ employment status } \\
\hline full-time & 211 & 61.5 & 217 & 63.3 \\
\hline part-time & 26 & 7.6 & 12 & 3.5 \\
\hline retired & 50 & 14.6 & 40 & 11.7 \\
\hline other & 56 & 16.3 & 74 & 21.6 \\
\hline \multicolumn{5}{|l|}{ residency } \\
\hline Pennsylvania & 158 & 46.1 & 283 & 82.5 \\
\hline out-of-state & 182 & 53.1 & 52 & 15.2 \\
\hline other & 3 & 0.9 & 8 & 2.3 \\
\hline
\end{tabular}

sylvania, whereas more than $80 \%$ of the controls resided in that state. Significant differences between the 2 patient groups were found for race, education, residency, history of cigarette smoking, alcohol consumption, occupational exposure to noise, regular cell phone use, history of hay fever or diabetes, and family history of cancer $(\mathrm{p}<0.05)$.

\section{Multivariate Analysis}

Results of the multivariate analyses are shown in Table 3. To evaluate exposure to medical radiation and VS, we built a conditional logistic regression model that adjusted for the potential confounding effect of all factors found significant in the bivariate analysis (race, education, residency, cigarette smoking, alcohol consumption, occupational exposure to noise, regular cell phone use, medical history of hay fever and diabetes, and a family history of cancer). Patients with VSs reported a significantly higher likelihood of exposure to dental x-rays than the control group, as shown in Table 3. An increased aOR was found among those "ever" having undergone a dental x-ray examination compared with those who reported "never" having undergone such an examination (aOR 4.26, 95\% CI 1.49-12.18). We also found that more frequent dental x-ray examinations were significantly associated with
VS: compared with patients who reported undergoing dental $\mathrm{x}$-ray examinations less than once every 5 years, the aOR was 2.65 (95\% CI 1.20-5.85) for those patients who reported undergoing dental $\mathrm{x}$-ray examinations once every 2-5 years and 2.27 (95\% CI 1.01-5.09) for those patients who reported undergoing dental x-ray examinations annually. However, no dose-response relationship was found. No significant association with VS was found when we looked at "ever" versus "never" responses about having undergone a CT or x-ray examination or radiation therapy directed to the head or neck $(\mathrm{aOR}=0.64,95 \%$ $\mathrm{CI}=0.39-1.06)$. When evaluated on its own, a CT study was found to be reported more frequently by patients in the control group $(\mathrm{aOR}=0.52,95 \% \mathrm{CI}=0.30-0.90)$; this may perhaps be related to the frequent use of this modality in patients with degenerative spinal disorders.

Results from the multivariate analysis of cell phone or cordless phone use are shown in Table 4. Regular cell phone use or use of a cell phone for longer than 10 years was not found more frequently in patients with VS (aOR $=0.95,95 \% \mathrm{CI}=0.58-1.58$ and $\mathrm{aOR}=1.29,95 \% \mathrm{CI}=$ 0.69-2.43, respectively). Similarly, a history of cordless phone use was not associated with VS (aOR $=0.93,95 \%$ $\mathrm{CI}=0.53-1.63)$. 
TABLE 2: Bivariate analysis of potential risk factors and confounders of vestibular schwannoma

\begin{tabular}{|c|c|c|c|}
\hline \multirow[b]{2}{*}{ Variable } & \multicolumn{2}{|c|}{ No. of Patients } & \multirow[b]{2}{*}{ p Value } \\
\hline & $\begin{array}{c}\text { VS Group } \\
\text { (343 patients) }\end{array}$ & $\begin{array}{l}\text { Control Group } \\
\text { (343 patients) }\end{array}$ & \\
\hline race & & & 0.003 \\
\hline white & 333 & 315 & \\
\hline other & 10 & 28 & \\
\hline education (yrs) & & & $<0.001$ \\
\hline$<13$ & 123 & 222 & \\
\hline$\geq 13$ & 220 & 121 & \\
\hline residency & & & $<0.001$ \\
\hline Pennsylvania & 158 & 283 & \\
\hline out-of-state/other & 185 & 60 & \\
\hline cigarette smoking & & & $<0.001$ \\
\hline never & 313 & 178 & \\
\hline former/current & 30 & 165 & \\
\hline alcohol consumption & & & 0.037 \\
\hline no & 98 & 123 & \\
\hline$\geq 1$ serving/wk & 245 & 220 & \\
\hline $\begin{array}{l}\text { occupational exposure to } \\
\text { noise }\end{array}$ & & & $<0.001$ \\
\hline no & 213 & 146 & \\
\hline yes & 130 & 197 & \\
\hline regular cell phone use* & & & 0.006 \\
\hline no & 140 & 172 & \\
\hline yes & 203 & 171 & \\
\hline medical history & & & \\
\hline asthma & & & 0.470 \\
\hline no & 310 & 303 & \\
\hline yes & 33 & 40 & \\
\hline hay fever & & & $<0.001$ \\
\hline no & 276 & 312 & \\
\hline yes & 67 & 31 & \\
\hline eczema & & & 0.163 \\
\hline no & 322 & 331 & \\
\hline yes & 21 & 12 & \\
\hline $\begin{array}{l}\text { other immunological dis- } \\
\text { ease }\end{array}$ & & & 0.503 \\
\hline no & 331 & 335 & \\
\hline yes & 12 & 8 & \\
\hline cancer & & & 0.488 \\
\hline no & 312 & 318 & \\
\hline yes & 31 & 25 & \\
\hline diabetes & & & 0.001 \\
\hline no & 330 & 306 & \\
\hline yes & 13 & 37 & \\
\hline prior history of head injury & & & 0.129 \\
\hline no & 282 & 266 & \\
\hline yes & 61 & 77 & \\
\hline family history of cancer & & & 0.001 \\
\hline no & 104 & 147 & \\
\hline yes & 239 & 196 & \\
\hline
\end{tabular}

* Regular cell phone is defined as use of a cell phone for at least 1 call per week during a 6-month period.

\section{Discussion}

\section{Vestibular Schwannoma and Medical Radiation}

During this matched case-control study we found that exposure to ionizing radiation associated with dental x-ray imaging was more commonly reported by the population of patients harboring VSs than by the control population with spinal disorders. This finding was maintained in a multivariate model that adjusted for other potential confounding factors such as sociodemographics, medical history, and environmental exposures. Exposure to ionizing radiation from other diagnostic imaging, nonionizing radiation from wireless phone technologies, and even prior therapeutic fractionated radiation therapy to the neck or head was not associated with an increased reported rate in our patients with VS.

Investigators from a previous matched case-control study reported that exposure to dental x-rays was significantly associated with an increased risk of thyroid cancer $(\mathrm{OR}=2.1,95 \% \mathrm{CI}=1.4-3.1)$ and the risk increased in a dose-response pattern adjusted for upper-body exposure to X-rays. ${ }^{15}$ However, Blettner et al. ${ }^{3}$ did not find that exposure to any medical radiation in the head and neck region resulted in an increased risk of VS (OR $=0.97,95 \%$ $\mathrm{CI}=0.54-1.75)$. Dental $\mathrm{x}$-ray exposures involving more than 5 full-mouth series have been reported to be associated with meningioma $(\mathrm{OR}=2.06,95 \% \mathrm{CI}=1.03-4.17) .{ }^{13}$ Although full-mouth or panorex exposures were reported more frequently by our patients with VS (42\%) than by patients in the control group (36\%), this relationship did not reach statistical significance in the multivariate analysis $(\mathrm{aOR}=1.04,95 \% \mathrm{CI}=0.62-1.75)$.

In the US, the per capita cumulative dose delivered during diagnostic radiological procedures increased sixfold between 1980 and 2006 (from 0.5 to $3.0 \mathrm{mSv}$ ), and approximately one-half of the individual medical dose is derived from the increased use of CT imaging. ${ }^{16}$ In the current study we found no increased use of CT or headand-neck imaging in the VS population. Exposure to any diagnostic cranial imaging before the age of 20 years has been associated with an increased risk of benign tumors of the parotid gland (relative risk $=1.8,95 \% \mathrm{CI}=$ 1.13-2.91). ${ }^{17}$ Epidemiological evidence for an association between CT imaging or head and neck radiation therapy and the risk of developing a brain tumor remains unclear. Assessing individual exposures by the type of imaging and the age at which the exposures occur will be necessary to further investigate the risk of developing a brain tumor as it relates to imaging examinations.

\section{Vestibular Schwannoma and Wireless Phone Technologies}

The large and growing number of cell phone users has raised concerns about the increasing exposure to low-dose radiofrequency radiation and the potential risk for brain tumors. Aside from the negative finding in our study, the final report of the INTERPHONE study, which included 1105 patients with VSs and 2145 controls in 13 countries, found no association between VS and regular cell phone use $(\mathrm{OR}=0.85,95 \% \mathrm{CI}=0.69-1.04)$ or use of cell phones for longer than 10 years $(\mathrm{OR}=0.76,95 \% \mathrm{CI}$ $=0.52-1.11) .^{5} \mathrm{~A}$ systematic review of 33 epidemiologi- 
Y. Y. Han et al.

TABLE 3: Conditional logistic regression analysis of vestibular schwannoma and medical radiation exposure*

\begin{tabular}{|c|c|c|c|}
\hline \multirow[b]{2}{*}{ Radiation Exposure } & \multicolumn{2}{|c|}{ No. of Patients } & \multirow[b]{2}{*}{$\mathrm{aOR}(95 \% \mathrm{Cl})$} \\
\hline & $\begin{array}{c}\text { VS Group } \\
\text { (343 patients) }\end{array}$ & $\begin{array}{l}\text { Control Group } \\
\text { (343 patients) }\end{array}$ & \\
\hline \multicolumn{4}{|l|}{ any dental or full-mouth/panorex x-ray } \\
\hline never & 11 & 33 & 1.00 \\
\hline ever & 332 & 310 & $4.26(1.49-12.18)$ \\
\hline \multicolumn{4}{|l|}{ dental x-ray } \\
\hline$<1$ time every 5 yrs & 42 & 92 & 1.00 \\
\hline 1 time every $2-5$ ys & 151 & 120 & $2.65(1.20-5.85)$ \\
\hline 1 time/yr & 150 & 131 & $2.27(1.01-5.09)$ \\
\hline \multicolumn{4}{|l|}{ full-mouth/panorex x-ray exam } \\
\hline never & 200 & 220 & 1.00 \\
\hline ever & 143 & 123 & $1.04(0.62-1.75)$ \\
\hline \multicolumn{4}{|c|}{ any CT scan, $x$-ray exam, or radiation treatment } \\
\hline never & 214 & 149 & 1.00 \\
\hline ever & 129 & 194 & $0.64(0.39-1.06)$ \\
\hline \multicolumn{4}{|l|}{ CT scan } \\
\hline never & 266 & 209 & 1.00 \\
\hline ever & 77 & 134 & $0.52(0.30-0.90)$ \\
\hline \multicolumn{4}{|l|}{$\mathrm{x}$-ray exam or radiation treatment } \\
\hline never & 240 & 180 & 1.00 \\
\hline ever & 103 & 163 & $0.61(0.37-1.00)$ \\
\hline
\end{tabular}

cal studies has estimated that the combined odds ratio for VS and cell phone use was $1.3(95 \% \mathrm{CI}=0.95-1.9) .{ }^{12}$ This study suggested an increased risk of brain tumors among cell phone users, but the magnitude cannot be assessed due to insufficient information on cell phone use. A higher risk of VS development has been noted among persons who started cell phone use before the age of 20

TABLE 4: Vestibular schwannoma and use of cell or cordless phone*

\begin{tabular}{lccc}
\hline & \multicolumn{2}{c}{ No. of Patients } & \\
\cline { 2 - 3 } \multicolumn{1}{c}{ Variable } & $\begin{array}{c}\text { VS Group } \\
\text { (343 patients) }\end{array}$ & $\begin{array}{c}\text { Control Group } \\
\text { (343 patients) }\end{array}$ & aOR $(95 \% \mathrm{Cl})$ \\
\hline $\begin{array}{l}\text { cell phone use } \\
\text { no }\end{array}$ & 140 & 171 & 1.00 \\
$\quad$ yes & 203 & 172 & $0.95(0.58-1.58)$ \\
cell phone use & & & \\
$\quad<10$ yrs & 111 & 120 & $0.79(0.45-1.37)$ \\
$\quad \geq 10$ yrs & 92 & 51 & $1.29(0.69-2.43)$ \\
$\begin{array}{l}\text { cordless phone use } \\
\text { no }\end{array}$ & 76 & & \\
$\quad$ yes & 267 & 270 & $0.93(0.53-1.63)$ \\
cordless phone use & & & \\
$\quad<10$ yrs & 197 & 222 & $0.91(0.52-1.60)$ \\
$\quad \geq 10$ yrs & 70 & 48 & $1.07(0.51-2.24)$ \\
\hline
\end{tabular}

* Model adjusting for race, education, cigarette smoking, alcohol consumption, occupational exposure to noise, history of hay fever or diabetes, and family history of cancer. years $(\mathrm{OR}=5.0,95 \% \mathrm{CI}=1.5-16) .^{7}$ The number of individuals who begin to use cell phones at younger ages has grown dramatically over the past decade. Although we did not find an increased incidence of VS among regular cell phone users, the risk of an age-dependent brain tumor and cumulative lifetime use of cell phones warrants further investigation.

\section{Limitations of the Current Study}

The self-reported exposure to diagnostic dental $\mathrm{x}$ ray or full-mouth or panorex x-ray examinations is likely an estimate of radiation exposure in the participants of this study. Recall bias and misclassification may occur if participants were unable to distinguish between different types of dental imaging. It is estimated that the usual radiation exposures during dental examinations are between 0.005 and $0.338 \mathrm{mSv} \cdot{ }^{14}$ It is very difficult to estimate a more precise dose in our study population due to changes in dental x-ray technology over time and the amount of user variability of different machines between dentists.

Our outpatient control group of patients with degenerative spinal disorders may not be an ideal representation of the general population. For instance, we found that a significantly greater proportion of control patients reported having undergone $\mathrm{CT}$ of the head or neck previously. Selection bias in the control group most likely explains this finding because patients with spinal degenerative disorders are more likely to have undergone CT imaging. Population-based controlled prospective studies will be able to further identify our findings. 


\section{Conclusions}

We found that patients with VSs reported a higher frequency of exposure to dental x-rays than age and sex-matched control patients with spinal degenerative disorders. Because of the underlying limitations of our retrospective study, future studies that include objective exposure measurements and longer observation periods may clarify this relationship. We also recommend further prospective evaluation of other types of medical radiation treatment directed to the head and neck in view of the dramatic increase in their use in recent years. Until such studies are available, it seems reasonable to try to reduce exposure to dental $\mathrm{x}$-ray imaging to further lessen the risk of developing a VS. This recommendation should be balanced against the potential value of more frequent dental imaging in the management of dental diseases.

\section{Disclosure}

This study was funded by a grant from the Jennie Zoline Foundation to the University of Pittsburgh Medical Center and support from the Center for Environmental Oncology-University of Pittsburgh Cancer Institute. Dr. Kondziolka is a consultant to Elekta AB. Dr. Lunsford is a consultant for and stockholder of Elekta AB.

Author contributions to the study and manuscript preparation include the following. Conception and design: Lunsford, Han, Berkowitz, Talbott. Acquisition of data: Han, Berkowitz, Talbott. Analysis and interpretation of data: Han, Berkowitz. Drafting the article: Han, Berkowitz, Donovan. Critically revising the article: all authors. Reviewed submitted version of manuscript: all authors. Approved the final version of the manuscript on behalf of all authors: Lunsford. Statistical analysis: Han, Berkowitz, Talbott. Administrative/technical/material support: Lunsford, Han, Berkowitz, Talbott. Study supervision: Lunsford, Han, Berkowitz, Talbott.

\section{References}

1. Agency for Toxic Substances and Disease Registry: Toxicological Profile for Ionizing Radiation. Atlanta: US Department of Health and Human Services, 1999 (http://www.atsdr. cdc.gov/toxprofiles/tp149.pdf) [Accessed May 7, 2012]

2. Benson VS, Green J, Pirie K, Beral V: Cigarette smoking and risk of acoustic neuromas and pituitary tumours in the Million Women Study. Br J Cancer 102:1654-1656, 2010

3. Blettner M, Schlehofer B, Samkange-Zeeb F, Berg G, Schlaefer K, Schüz J: Medical exposure to ionising radiation and the risk of brain tumours: Interphone study group, Germany. Eur J Cancer 43:1990-1998, 2007

4. Brenner AV, Linet MS, Fine HA, Shapiro WR, Selker RG, Black PM, et al: History of allergies and autoimmune diseases and risk of brain tumors in adults. Int J Cancer 99:252-259, 2002

5. Cardis E, Deltour I, Vrijheid M, Evrad AS, Sanchez M, Moissonnier M, et al: Acoustic neuroma risk in relation to mobile telephone use: results of the INTERPHONE international case-control study. Cancer Epidemiol 35:453-464, 2011

6. Edwards CG, Schwartzbaum JA, Lönn S, Ahlbom A, Feychting $\mathrm{M}$ : Exposure to loud noise and risk of acoustic neuroma. Am J Epidemiol 163:327-333, 2006

7. Hardell L, Carlberg M: Mobile phones, cordless phones and the risk for brain tumours. Int J Oncol 35:5-17, 2009
8. Hill DA, Linet MS, Black PM, Fine HA, Selker RG, Shapiro WR, et al: Meningioma and schwannoma risk in adults in relation to family history of cancer. Neuro-oncol 6:274-280, 2004

9. Hours M, Bernard M, Arslan M, Montestrucq L, Richardson L, Deltour I, et al: Can loud noise cause acoustic neuroma? Analysis of the INTERPHONE study in France. Occup Environ Med 66:480-486, 2009

10. International Agency for Research on Cancer: IARC Classifies Radiofrequency Electromagnetic Fields as Possibly Carcinogenic to Humans. Lyon: World Health Organization, 2011 (http://www.iarc.fr/en/media-centre/pr/2011/pdfs/ pr208_E.pdf) [Accessed May 7, 2012]

11. Kleinerman RA, Linet MS, Hatch EE, Tarone RE, Black PM, Selker RG, et al: Self-reported electrical appliance use and risk of adult brain tumors. Am J Epidemiol 161:136-146, 2005

12. Kundi M: The controversy about a possible relationship between mobile phone use and cancer. Environ Health Perspect 117:316-324, 2009

13. Longstreth WT Jr, Phillips LE, Drangsholt M, Koepsell TD, Custer BS, Gehrels JA, et al: Dental X-rays and the risk of intracranial meningioma: a population-based case-control study. Cancer 100:1026-1034, 2004

14. Ludlow JB, Davies-Ludlow LE, White SC: Patient risk related to common dental radiographic examinations: the impact of 2007 International Commission on Radiological Protection recommendations regarding dose calculation. J Am Dent Assoc 139:1237-1243, 2008

15. Memon A, Godward S, Williams D, Siddique I, Al-Saleh K: Dental x-rays and the risk of thyroid cancer: a case-control study. Acta Oncol 49:447-453, 2010

16. Mettler FA Jr, Bhargavan M, Faulkner K, Gilley DB, Gray JE, Ibbott GS, et al: Radiologic and nuclear medicine studies in the United States and worldwide: frequency, radiation dose, and comparison with other radiation sources-1950-2007. Radiology 253:520-531, 2009

17. Preston-Martin S, Thomas DC, White SC, Cohen D: Prior exposure to medical and dental x-rays related to tumors of the parotid gland. J Natl Cancer Inst 80:943-949, 1988

18. Rouleau GA, Merel P, Lutchman M, Sanson M, Zucman J, Marineau $\mathrm{C}$, et al: Alteration in a new gene encoding a putative membrane-organizing protein causes neuro-fibromatosis type 2. Nature 363:515-521, 1993

19. Wrensch M, Miike R, Lee M, Neuhaus J: Are prior head injuries or diagnostic X-rays associated with glioma in adults? The effects of control selection bias. Neuroepidemiology 19: 234-244, 2000

Manuscript submitted March 23, 2012.

Accepted May 3, 2012.

Portions of this work were presented in poster form at the Leksell Gamma Knife Society Meeting in Sydney, Australia, in March 2012. This work also contributed in part to the doctoral dissertation of Oren Berkowitz, Ph.D., which was successfully defended on September 29, 2011, at the Graduate School of Public Health, University of Pittsburgh.

Please include this information when citing this paper: DOI: 10.3171/2012.5.GKS12615.

Address correspondence to: L. Dade Lunsford, M.D., Department of Neurological Surgery, Suite B-400, UPMC Presbyterian Hospital, 200 Lothrop Street, Pittsburgh, Pennsylvania 15213. email: lunsfordld@upmc.edu. 